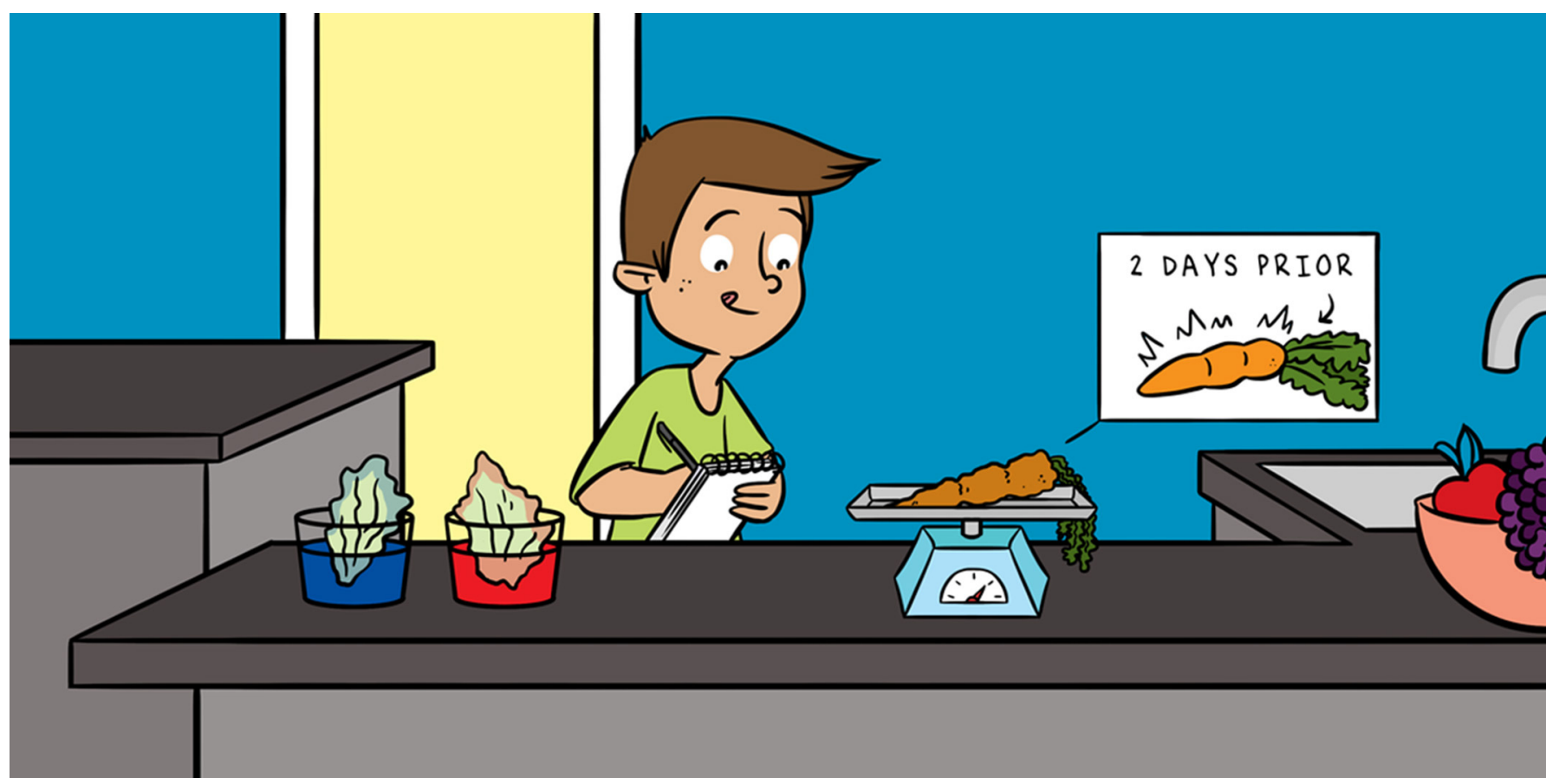

\title{
KEEPING FRUITS AND VEGETABLES FRESH BY LIMITING RESPIRATION AND TRANSPIRATION
}

\section{Graziele G. Bovi ${ }^{* t}$ and Werner B. Herppich}

Department of Horticultural Engineering, Leibniz Institute for Agricultural Engineering and Bioeconomy (ATB), Potsdam, Germany

YOUNG REVIEWER:

MARTA

AGE: 14
In this article, we will explain the processes of transpiration and respiration in plants. Also, we will explain how to keep fruits and vegetables fresh for longer periods by limiting respiration and transpiration. You will furthermore learn how to measure these processes and to visualize the process of transpiration in a very colorful manner at home through a very simple experiment. In addition, by the end of this article, we will help you answer many "whys" related to respiration and transpiration in plants, specifically in fruits and vegetables.

\section{HAVE YOU EVER WONDERED}

- Why do bananas (and other fruits and vegetables) shrink when left uncovered on the kitchen shelf for some time?

- Why do we keep most of our fruits and vegetables (F\&V) in the refrigerator? Don't you or your parents do that especially with leafy vegetables? 


\section{TRANSPIRATION}

The process by which water vapor is released from the surfaces of plants, flowers, fruits, or vegetables.

\section{RESPIRATION}

The process used by plants to generate energy. Oxygen and stored sugars are used and carbon dioxide and water are produced.

\section{XYLEM}

The tissue in which plants transport water and nutrients from the roots to the rest of the plant.

Figure 1

(A) In the process of transpiration, water evaporates into the air from the surface of a plant and is replaced by water taken up by the roots. A tube-like plant tissue called xylem transports water, and the nutrients it contains, from the roots to the other parts of the plant. (B) In the process of respiration, plants use oxygen, and stored sugars to produce energy, water and carbon dioxide.
- Why can you sometimes find water inside F\&V packages even though they were dry before? Was that magic or could it come from the F\&V?

Well, these questions can be easily answered if we understand the processes of transpiration and respiration in plants. So, let this article guide you on answering all these "whys" you might have ever wondered.

\section{WHAT IS TRANSPIRATION?}

Transpiration is the process by which water exits from plants (Figure 1A). Liquid water inside leaves and other plant parts evaporates, and the resulting water vapor moves out into the surrounding air. Normally, plants can easily replace this "lost" water by taking up water from the soil, with the help of their roots. This water is transported up the stems to the leaves, through a specialized tube-like tissue called xylem. Plants also acquire valuable nutrients from the soil water and transport these nutrients to the leaves and other plant parts. Nutrient uptake is one major purpose of transpiration in plants. The other purpose is to cool the leaves when it is hot outside. You have probably experienced this cooling effect yourself when water evaporates from your skin after you get out of a swimming pool. The process of transpiration helps us humans, animals and plants to keep cool, cool right?

Transpiration happens in all kinds of plants, including herbs, shrubs, and trees. It also happens in harvested roots, stems, flowers, or fruit. Even if fruits and vegetables (F\&V) are separated from the plant, they continue to transpire and, therefore, to lose water. The difference is that detached F\&V cannot replace the water that they lose. In $\mathrm{F} \& \mathrm{~V}$, transpiration results in shrinking, shriveling, decreased glossiness, and wilting. As F\&V continue to lose water, their appearance, quality,

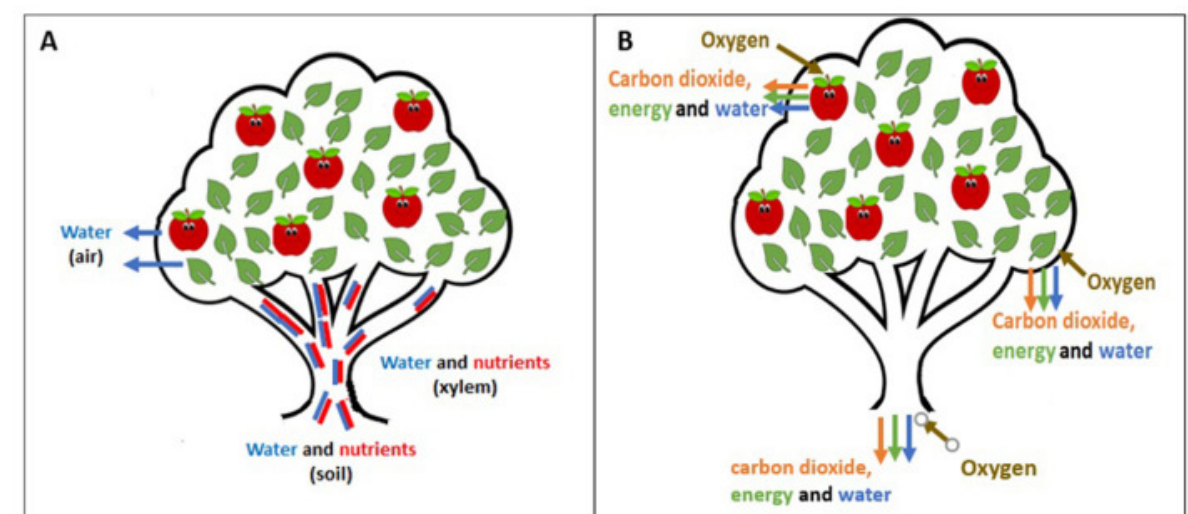

Figure 1 


\section{SHELF LIFE}

The length of time that a food product is good to eat and therefore able to be sold.

\section{HUMIDITY}

A measure of the amount of water vapor in the air. shelf life, and consumer appeal decrease [1]. You have probably noticed this happening with F\&V in your kitchen. Don't they eventually get smaller and less attractive to eat? Well, you can blame transpiration for that!

The amount of water lost in transpiration is related to the plant's surface area and the characteristics of the skin, or peel, of F\&V. Water exits plants through their skin. For that reason, leafy green vegetables and vegetables like cauliflower, which have large surface areas, transpire more than oranges or tomatoes, because spherical fruits have lower surface areas. Now let us compare an apple and a mushroom. Which one has a thicker skin? Apples, right? So, it is much harder for water to leave through the thick, waxy apple peel than through the surface of a mushroom, which has no skin. Therefore, the shape, size, and structure of a plant all affect transpiration.

Other factors, such as maturity stage, skin injuries, temperature, air flow, and humidity, can also affect transpiration. For example, the higher the temperature and the lower the humidity, the higher the transpiration of F\&V. To demonstrate this, we measured the transpiration of picked strawberries at different temperatures and humidities [2]. As we increased the temperature from 4 to $20^{\circ} \mathrm{C}$, which also decreased the humidity, transpiration increased more than five times!

\section{MEASURING AND VISUALIZING TRANSPIRATION}

You can easily measure transpiration at home. All you need is a fruit or vegetable of your preference, a kitchen scale, paper, and a pen. Keep track of the mass of your chosen piece of produce over a period of several days. As time passes, you will see that your produce becomes lighter and lighter. Most of this mass loss corresponds to the water lost via transpiration. You can even calculate the percentage of your produce's mass that has been lost over time via transpiration, by solving the following equation:

$$
\text { Mass loss }(\%)=\frac{M_{i}-M_{t}}{M_{i}} \times 100
$$

where $M_{i}$ is the initial mass of the product and $M_{t}$ is the final mass.

You can also visualize the transpiration process using a simple but interesting experiment. All you need are some lettuce leaves, water, food coloring, and a clear drinking glass or transparent pot. Fill the glass about 1/3 full of water. Mix some food coloring with the water, enough to make the water dark. Use multiple glasses with different colored water if you like! Put the lettuce leaves into the water (Figure 2A). After a couple of hours, you will begin to see the leaves becoming more colorful as they transpire. The leaves suck up colored water from 
Figure 2

Visualizing

transpiration. (A)

Lettuce leaves

immediately after being

placed into colored

water. (B) Lettuce

leaves after a couple of

hours in colored water.

(C) White flowers

immediate after being

placed into colored

water. (D) Flowers after

a couple of hours in

colored water. In (B,D),

you can clearly see

some of the effects of

transpiration on the

lettuce and flowers,

such as shrinking,

decreased glossiness,

and wilting.

\section{GAS EXCHANGE}

Movement of a gas from an area of high concentration, an area where there is a lot of it, to an area of low concentration.
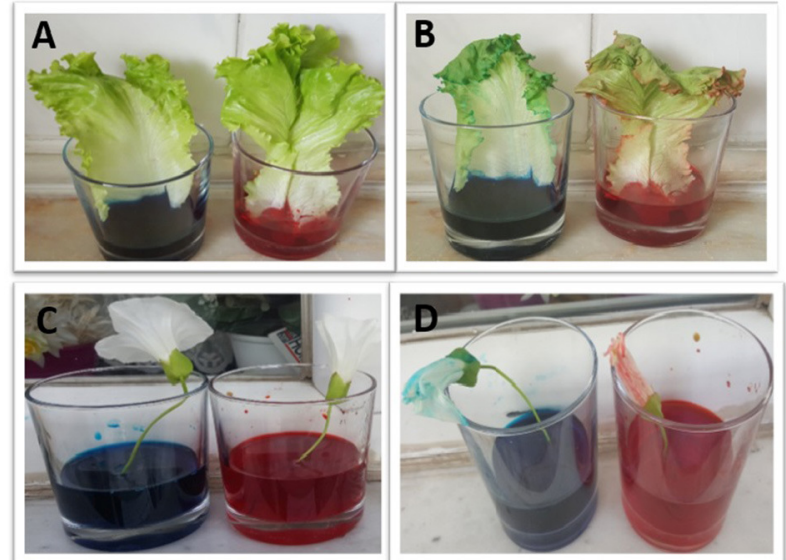

Figure 2

the glass and transport it to the leaf surface, where it evaporates (Figure 2B). This also works with leaves from celery, turnip, cabbage, or with white-petaled flowers (Figures 2C,D).

\section{WHAT IS RESPIRATION?}

In very simple terms, in respiration plants "inhale" oxygen $\left(\mathrm{O}_{2}\right)$ from the air (at night) and "exhale" carbon dioxide $\left(\mathrm{CO}_{2}\right)$, just as you do by breathing. For humans, animals and plants, this gas exchange, however, is only one part of the entire story. In the full process of respiration, plants consume sugars, or in the case of avocados, e.g., fats and oxygen, and produce carbon dioxide, water and heat in the cells (Figure 1B) [3]. In other words, we can say that respiration is the process in which "food" is broken down with the help of oxygen to produce energy.

But you may say, plants do not eat (ok, e.g., except Venus flytraps); how do they get their food then? Well, you certainly know what photosynthesis is. During the day, plants can "reverse" respiration, take up $\mathrm{CO}_{2}$ from the air and water from the soil, and, with the help of absorbed sun light energy, produce sugars, and $\mathrm{O}_{2}$.

Just as we saw for transpiration, many factors can affect the respiration of F\&V. These factors are often divided into two groups: those that affect the growth of F\&V before harvest and those that are relevant after harvest. Before harvest, the season and the climate influence the amount that F\&V respire. For respiration, temperature is a very important factor. The higher the temperature, the more F\&V will respire. So, on a hot day, the same F\&V will respire more than it will on a cold day. After harvest, temperature and the $\mathrm{O}_{2}$ and $\mathrm{CO}_{2}$ concentrations around the $\mathrm{F} \& \mathrm{~V}$ both affect respiration. To demonstrate this, we measured the respiration rates of picked strawberries at different temperatures [2]. When the temperature was 


\section{FERMENTATION}

Chemical processes related to respiration that happen in plants and animals if only low oxygen concentration is available.

\section{MODIFIED}

ATMOSPHERE

\section{PACKAGING}

A special type of food packaging that helps modifying the gas composition inside packages and, thus, reduces respiration but increases shelf life. increased from 4 to $20^{\circ} \mathrm{C}$, the respiration of the fruit increased by more than five times!

Respiration can also affect shelf life of $F \& V$, for example, if $F \& V$ no longer have $\mathrm{O}_{2}$ to take in, it will undergo another process called fermentation, which will produce strong taste and smell. But do not go on thinking that fermentation is always a bad thing. For some products, such as yogurt, it is a good thing, but for others such as fresh F\&V it is not.

\section{MEASURING RESPIRATION}

Measuring plant respiration at home is a bit more complicated, so you might want to leave this one to the scientists. The measuring process requires an airtight box or other container that prevents air from coming in or out. Oxygen and carbon dioxide sensors are also needed. These tools measure and record the amount of $\mathrm{O}_{2}$ and $\mathrm{CO}_{2}$ in the air. A fruit or vegetable is sealed into the airtight container and, over time, the chosen piece of produce will use up some $\mathrm{O}_{2}$ and generate some $\mathrm{CO}_{2}$ by respiration, decreasing the $\mathrm{O}_{2}$ concentration and increasing the $\mathrm{CO}_{2}$ concentration in the airtight box. The sensors record these changes [4].

\section{HOW CAN WE KEEP FRUITS AND VEGETABLES FRESH LONGER?}

We are sure you already take steps at home to keep your F\&V fresh! First, you probably keep them in the refrigerator. Refrigeration helps F\&V to last longer, because temperature is a key factor affecting both transpiration and respiration. So, just by keeping your F\&V in the refrigerator, you slow down both respiration and transpiration, which helps your produce to last longer.

It is important to know that every F\&V has unique storage conditions. The two most important factors are temperature and humidity (Table 1). Most F\&V prefer a high humidity of $85-90 \%$. But there are some products that last longer at lower humidity, such as garlic and onion, which prefer humidity of $70-75 \%$. Lower humidity helps these products to avoid absorbing water, which could lead to them becoming moldy and spoiling.

Packaging is another simple technique for keeping F\&V fresh. Nearly any package is helpful, even a paper bag. Packaging leads to a higher humidity around the F\&V and, therefore, slows down transpiration. Many companies use a specific kind of packaging called modified atmosphere packaging, which can be seen quite often in supermarkets. This type of packaging is specially designed to reduce the respiration of $\mathrm{F} \& \mathrm{~V}$, by modifying the concentration of oxygen 


\section{Table 1}

Optimum storage conditions for some F\&V [5].

\begin{tabular}{llccl} 
Plant & Product & Temperature $\left({ }^{\circ} \mathbf{C}\right)$ & Humidity $(\%)$ & Shelf life \\
\hline \multirow{7}{*}{ Fruits } & Mango & $10-12$ & $85-90$ & 4 weeks \\
& Orange & $0-9$ & $90-95$ & $3-8$ weeks \\
& Lemon & $10-13$ & $85-90$ & $1-6$ months \\
& Green tomato & $18-20$ & $90-95$ & 2 weeks \\
& Ripe tomato & $13-15$ & $90-95$ & $4-7$ days \\
& Eggplant & $7-12$ & $85-90$ & $7-10$ days \\
& Carrot & 0 & $95-98$ & $6-9$ months \\
& Broccoli & 0 & $95-98$ & $1-2$ weeks \\
& Cauliflower & 0 & $95-98$ & $3-4$ weeks \\
& Cucumber & $10-12$ & 95 & 2 weeks \\
\hline
\end{tabular}

Table 1

available for the F\&V to use [6]. Usually, there is less oxygen and more carbon dioxide inside these packages than is found in the air outside the package.

\section{TIME TO ANSWER ALL THE "HAVE YOU EVER WONDERED" QUESTIONS}

- Why do bananas (and other fruits and vegetables) shrink when left uncovered on the kitchen shelf for some time?

Well, by now you have already learned that fruits transpire and respire. In the process of transpiration, the plants lose water and, consequently, they also lose some mass. In the process of respiration, the breakdown of sugar into carbon dioxide, water, and heat also leads to mass loss.

- Why do we keep most of our fruits and vegetables (F\&V) in the refrigerator? Don't you or your parents do that especially with leafy vegetables?

As we have explained before, both respiration and transpiration depend on temperature. The lower temperatures limit both processes and, therefore, these processes are slowed down, which increases the shelf life of F\&V. In the case of leafy vegetables, lettuce for example, they will wilt very quickly if left outside, especially on a hot and dry day.

- Why can you sometimes find water inside F\&V packages even though they were dry before? Was that magic or could it come from the F\&V? 
No magic here! The water comes from the F\&V; it is simply the water released by transpiration. This water vapor condensed inside the package.

Well, we hope that you enjoyed learning about respiration and transpiration. Have fun with measuring and visualizing transpiration at home, share it with your parents and friends!

\section{REFERENCES}

1. Bovi, G. G., Caleb, O. J., Linke, M., Rauh, C., and Mahajan, P. V. 2016. Transpiration and moisture evolution in packaged fresh horticultural produce and the role of integrated mathematical models: a review. Biosyst. Eng. 150:24-39. doi: 10.1016/j.biosystemseng.2016.07.013

2. Bovi, G. G., Rux, G., Caleb, O. J., Herppich, W. B., Linke, M., Rauh, C., et al. 2018. Measurement and modelling of transpiration losses in packaged and unpackaged strawberries. Biosyst. Eng. 174:1-9. doi: 10.1016/j.biosystemseng. 2018.06.012

3. Caleb, O. J., Herppich, W. B., and Mahajan, P. V. 2016. "The basics of respiration for horticultural products," in Reference Module in Food Science (Elsevier). p. 1-7. doi: 10.1016/B978-0-08-100596-5.21003-2

4. Bovi, G. G., Caleb, O. J., Herppich, W. B., and Mahajan, P. V. 2018. "Mechanisms and modeling of water loss in horticultural products," in Reference Module in Food Science (Elsevier). p. 1-5. doi: 10.1016/B978-0-08-100596-5.21897-0

5. Paltrinieri, G. 2014. Handling of Fresh Fruits, Vegetables and Root Crops: $A$ Training Manual for Grenada. Food and Agriculture Organization of the United Nations.

6. Bovi, G. G., Caleb, O. J., Ilte, K., Rauh, C., and Mahajan, P. V. 2018. Impact of modified atmosphere and humidity packaging on the quality, off-odour development and volatiles of 'Elsanta' strawberries. Food Packag. Shelf Life 16:204-10. doi: 10.1016/j.fpsl.2018.04.002

SUBMITTED: 28 August 2020; ACCEPTED: 02 July 2021; PUBLISHED ONLINE: 02 August 2021.

EDITED BY: Melissa Hamner Mageroy, Norwegian Institute of Bioeconomy Research (NIBIO), Norway

CITATION: Bovi GG and Herppich WB (2021) Keeping Fruits And Vegetables Fresh By Limiting Respiration And Transpiration. Front. Young Minds 9:576906. doi: 10. 3389/frym.2021.576906

CONFLICT OF INTEREST: The authors declare that the research was conducted in the absence of any commercial or financial relationships that could be construed as a potential conflict of interest.

COPYRIGHT @ 2021 Bovi and Herppich. This is an open-access article distributed under the terms of the Creative Commons Attribution License (CC BY). The use, distribution or reproduction in other forums is permitted, provided the original 

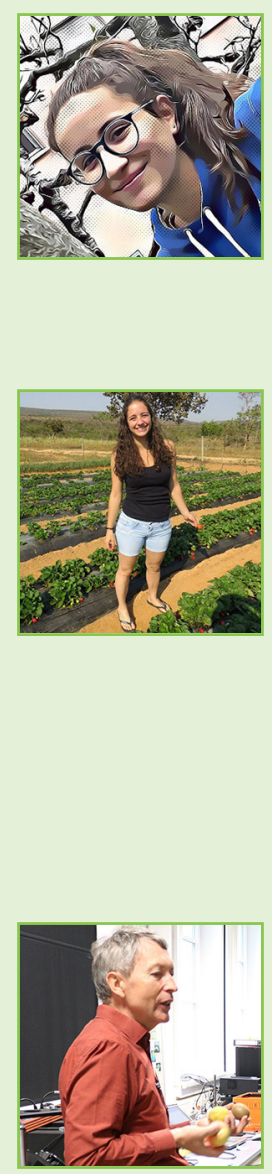

author(s) and the copyright owner(s) are credited and that the original publication in this journal is cited, in accordance with accepted academic practice. No use, distribution or reproduction is permitted which does not comply with these terms.

\section{YOUNG REVIEWER}

\section{MARTA, AGE: 14}

My name is Marta, I am 14 years old and I live in Italy. I play volleyball. In my free time I like meeting my friends and reading. My favorite book is Harry Potter. I also like listening to music.

\section{AUTHORS}

\section{GRAZIELE G. BOVI}

Graziele G. Bovi studied food engineering at the University of São Paulo in Brazil. After graduation she proceeded in academia and finalized a Ph.D. study at the Technical University of Berlin in Germany. She worked in the area of nanoencapsulation and later with packaging and storage of fruits and vegetables. Outside her research, she enjoys jogging, traveling, cooking, reading, and watching TV series. *graziele.bovi@gmail.com

${ }^{\dagger}$ Present address: Department of Food Engineering, School of Food Engineering, University of Campinas, Campinas, Brazil

\section{WERNER B. HERPPICH}

Werner B. Herppich studied biology and chemistry at the University of Bayreuth in Germany, but later concentrated on ecological plant physiology and investigated the mechanisms of plant survival in harsh environments such as hot deserts or high saline habitats for and after his Ph.D. For a while, he worked as a teacher but has now been involved in optimizing the shelf life of fruits, vegetables and ornamentals for more than 20 years. Besides this, he is fond of bicycling, (mountain) hiking, science fiction, aviation, and collecting stamps. 